\title{
Polymorphism at the Adh and $\alpha$ Gpdh loci in Drosophila melanogaster: effects of rearing temperature on developmental rate, body weight, and some biochemical parameters
}

\author{
L. OUDMAN, W. VAN DELDEN, A. KAMPING \& R. BIJLSMA \\ Department of Genetics, University of Groningen, P.O. Box 14, 9750 AA Haren, The Netherlands
}

\begin{abstract}
The role of developmental time in the world-wide cline of $A d h$ and $\alpha G p d h$ allele frequencies of Drosophila melanogaster, and the relationship with weight and some biochemical characters, were investigated. Experimental strains were constructed with different combinations of $A d h$ and $\alpha G p d h$ alleles but with similar genetic background. Developmental time, adult weight, protein-and triglyceride-content, and $\mathrm{ADH}$ and $\alpha \mathrm{GPDH}$ enzyme activity were measured at a rearing temperature of 20,25 and $29^{\circ} \mathrm{C}$. Genotype effects were found in all studied characters. In general the developmental times of genotypes were: $A d h^{\mathrm{FF}}<A d h^{\mathrm{FS}}<A d h^{\mathrm{SS}}$ and $\alpha G p d h^{\mathrm{FF}}>\alpha G p d h^{\mathrm{FS}}=$ $\alpha G p d h^{\text {ss }}$. Developmental time and adult weight were strongly affected by rearing temperature. Triglyceride content and $\mathrm{ADH}$ and $\alpha \mathrm{GPDH}$ enzyme activity were slightly affected by temperature. Interactions between genotype and temperature effects were found for developmental rate, adult weight and protein content. No trade off was observed between developmental time on the one hand and adult weight, protein- and triglyceride-content, and $\mathrm{ADH}$ and $\alpha \mathrm{GPDH}$ enzyme activity on the other hand. It is argued that developmental rate differences might be one of the underlying mechanisms of the world-wide cline of the $A d h$ and $\alpha G P d h$ allele frequencies.
\end{abstract}

Keywords: Adh, $\alpha$ Gpdh, developmental time, Drosophila melanogaster, temperature, weight.

\section{Introduction}

The alcohol dehydrogenase $(A d h)$ and $\alpha$-glycerophosphate dehydrogenase ( $\alpha G p d h$ ) loci are two of the most extensively studied allozyme systems of Drosophila melanogaster. They provide an excellent opportunity to study interactions between physiological effects of gene-enzyme systems. Both loci have two common electrophoretic alleles: $A d h^{\mathrm{F}}, A d h^{\mathrm{S}}, \alpha G p d h^{\mathrm{F}}$ and $\alpha G p d h^{\mathrm{S}}$. Nearly all natural populations are polymorphic for both loci. The frequencies of these alleles show world-wide clinal variation: the frequencies of $A d h^{\mathrm{S}}$ and $\alpha G p d h^{\mathrm{F}}$ decrease with increasing latitude (Oakeshott et al., 1982). An important question is whether these clines are under the control of natural selection. Correlation analysis of climatic data revealed no consistent significant correlations (Anderson et al., 1987). In the laboratory, stress from alcohol or temperature can cause differential selection of $A d h$ and $\alpha G p d h$ alleles (e.g. Van Delden, 1982; Zera et al., 1985). Under normal laboratory conditions equi- librium selection has been demonstrated for $A d h$ (Bijlsma-Meeles \& Bijlsma, 1988) and $\alpha G p d h$ (Palabost-Charles, 1980). Selection at temperatures between 25 and $30^{\circ} \mathrm{C}$ may lead to an increase of the $A d h^{\mathrm{s}}$ and $\alpha G p d h^{\mathrm{F}}$ alleles (Alahiotis, 1982; Van Delden, 1984). Vigue et al. (1982) and Oakeshott et al. (1985), however, found no effect of temperature on $A d h$ or $\alpha G p d h$ allele frequencies. Van Delden (1984) and Van Delden \& Kamping (1989) ascribe the advantage of the $A d h^{\mathrm{S}}$ and $\alpha G p d h^{\mathrm{F}}$ alleles at a higher temperature, for the greater part, to linkage of both alleles with the inversion $\operatorname{In}(2 L) t$.

Differences in developmental time between genotypes may be an important underlying mechanism of selection. Developmental rate is a quantitative trait in which many biochemical processes play a role (Robertson, 1963). ADH and $\alpha \mathrm{GPDH}$ may be two of the enzymes involved: differences in developmental rate between genotypes are described for both $A d h$ and aGpdh (e.g. Kohane \& Parsons, 1986; Barnes et al., 1989; Izquierdo \& Rubio, 1989). The fitness interac- 
tion between $A d h$ and $\alpha G p d h$ is described by Cavener \& Clegg (1981) who followed $A d h$ and $\alpha G p d h$ allele frequencies of populations on medium with ethanol. McKechnie \& Geer (1988) describe epistatic interactions between $A d h$ and $\alpha G p d h$ alleles in larval ethanol tolerance. Metabolic interaction between $\mathrm{ADH}$ and $\alpha$ GPDH is plausible in two biochemical pathways.

1 Both enzymes influence the $\mathrm{NADH} / \mathrm{NAD}^{+}$ratio (Cavener, 1983): the oxidation of ethanol by ADH generates $\mathrm{NADH}, \alpha \mathrm{GPDH}$ regenerates $\mathrm{NAD}^{+}$in concert with mitochondrial $\alpha$ GPO to form the ' $\alpha$ GPDHshuttle'(O’Brien \& MacIntyre, 1978).

2 Both enzymes play a role in lipid synthesis (Geer et al., 1983): ethanol, oxidized by ADH, becomes for the greater part incorporated in fatty acids, while $\alpha \mathrm{GPDH}$ produces glycerophosphate, a precursor of phospholipids and triglycerides.

The present article describes measurements of the rate of development for $A d h \alpha G p d h$ genotypes at different pre-adult temperatures under normal laboratory conditions. Because of a possible trade off with developmental time, adult body weight and protein and triglycerides content were measured. $\mathrm{ADH}$ and $\alpha$ GPDH enzyme activities were measured to investigate the relations with the previous mentioned parameters. The results are discussed in relation to the world-wide clinal variation in $A d h$ and $\alpha G p d h$ allele frequencies.

\section{Materials and methods}

\section{Experimental stocks}

Sublines, homozygous for $A d h^{\mathrm{F}}$ or $A d h^{\mathrm{S}}$ and $\alpha G p d h^{\mathrm{F}}$ or $\alpha G p d h^{\mathrm{S}}$, were derived from the polymorphic wildtype laboratory strain Groningen 83 . This strain was founded in 1983 with 403 females from a fruit market in Groningen, The Netherlands. At the time the sublines were derived the allele frequencies in the strain were 19 per cent $A d h^{\mathrm{s}}$ and 8 per cent $\alpha G p d h^{\mathrm{s}}$. Eight single pairs were selected which contained both $A d h$ and both $\alpha G p d h$ alleles. From each of these eight pairs a quartet of sublines, each homozygous for one of the four possible combinations of $A d h$ and $\alpha G p d h$ alleles, was derived by four subsequent single-pair crosses for each of the genotypes. The eight quartets (1-8) were combined into two sets using the same genotypes from the quartets $1-4(\mathrm{~A})$ and idem for the quartets 5-8 (B). This resulted in two sets (A and B) with a similar genetic background within each set. The strains were checked for the occurrence of the inversion $\operatorname{In}(2 L) t$ by scoring recombination with the mutants dumpy and black (Van Delden \& Kamping, 1989); this inversion did not occur. Lines were obtained for the experiments from crosses between sets $\mathrm{A}$ and $\mathrm{B}$, resulting in $A d h a G p d h$ genotypes with a similar genetic background $(\mathrm{A} \times \mathrm{B})$. Nine crosses (and their reciprocals) were performed to obtain all possible $A d h \alpha G p d h$ genotypes, see Table 1. For statistical reasons only one double heterozygous genotype was used.

\section{Rearing conditions}

Standard medium was prepared according to Mittler \& Bennet (1962) with slight modifications: $1000 \mathrm{ml}$ water, $19 \mathrm{~g}$ agar, $54 \mathrm{~g}$ sucrose, $32 \mathrm{~g}$ sterilized dry yeast and $13 \mathrm{ml}$ nipagine solution (10 $\mathrm{g}$ nipagine in $100 \mathrm{ml}$ 96 per cent ethanol). All incubators had $24 \mathrm{~h}$ light and $\sim 50$ per cent $\mathrm{RH}$. To obtain the parental generation, flies from the sets A and B were allowed to lay eggs for $10 \mathrm{~h}$ on dishes with fresh medium. The eggs were transferred to $250 \mathrm{ml}$ bottles with $30 \mathrm{ml}$ fresh medium, 200 eggs per bottle, and incubated at $25^{\circ} \mathrm{C}$. After eclosion, virgin females and males were collected and the sexes were aged separately for 5 days in vials. The flies were crossed according to the scheme given in Table 1. Reciprocal crosses were kept separately. Flies were stored in bottles, supplied with live yeast. After 3 days flies were allowed to lay eggs for $4 \mathrm{~h}$ on dishes with fresh medium and a drop of live yeast. The eggs were washed from the medium (with water of $25^{\circ} \mathrm{C}$ ) and sets of 50 eggs were put in plastic vials of $80 \times 23 \mathrm{~mm}$ with $8 \mathrm{ml}$ fresh medium. Twelve hours after egg laying the vials were put at the appropriate temperature $\left(20,25\right.$ or $\left.29^{\circ} \mathrm{C}\right)$. Five vials were incubated at each temperature for each cross. There were no differences in survival between the genotypes. The mean survival from egg to adult was 88 per cent.

Table 1 Origin of the experimental lines from the sets $\mathrm{A}$ and B. The first and second letter refer to the $A d h$ genotype, the third and fourth letter to the $\alpha G p d h$ genotype

\begin{tabular}{|c|c|c|c|c|}
\hline & \multicolumn{4}{|l|}{ Set B } \\
\hline & $\begin{array}{l}A d h^{\mathrm{FF}} \\
\alpha G p d h^{\mathrm{FF}}\end{array}$ & $\begin{array}{l}A d h^{\mathrm{FF}} \\
\alpha G p d h^{\mathrm{sS}}\end{array}$ & $\begin{array}{l}A d h^{\mathrm{ss}} \\
\alpha G p d h^{\mathrm{FF}}\end{array}$ & $\begin{array}{l}A d h^{\mathrm{ss}} \\
\alpha G p d h^{\mathrm{ss}}\end{array}$ \\
\hline \multicolumn{5}{|l|}{ Set A } \\
\hline $\begin{array}{l}A d h^{\mathrm{FF}} \\
\alpha G p d h^{\mathrm{FF}}\end{array}$ & FF FF & FF FS & & FS FS \\
\hline $\begin{array}{l}A d h^{\mathrm{FF}} \\
\alpha G p d h^{\mathrm{sS}}\end{array}$ & & FF SS & & FS SS \\
\hline $\begin{array}{l}A d h^{\mathrm{SS}} \\
\alpha G p d h^{\mathrm{FF}}\end{array}$ & FS FF & & SS FF & \\
\hline $\begin{array}{l}A d h^{\mathrm{ss}} \\
\alpha G p d h^{\mathrm{ss}}\end{array}$ & & & SS FS & SS SS \\
\hline
\end{tabular}




\section{Developmental time}

Flies were removed after eclosion at regular intervals depending on temperature $\left(\sim 8 \mathrm{~h}\right.$ at $20^{\circ} \mathrm{C}$; $\sim 6 \mathrm{~h}$ at $25^{\circ} \mathrm{C}$; $\sim 4 \mathrm{~h}$ at $29^{\circ} \mathrm{C}$ ), counted and stored in vials at $25^{\circ} \mathrm{C}$, for weight determination and biochemical assays. The developmental time of individual flies was taken as the midpoint of the interval. The developmental time per vial was calculated as the average of the developmental times of the individual flies.

\section{Adult weight}

The flies were etherized a few hours after collecting, the sexes separated and aged separately for 6 days at $25^{\circ} \mathrm{C}$ in vials with 20 flies each. On the sixth day the flies were etherized and weighed in groups of 10 (five replicates) to an accuracy of $0.01 \mathrm{mg}$. Immediately after weighing each group was stored at $-80^{\circ} \mathrm{C}$ for later assay of protein, triglycerides and $\alpha \mathrm{GPDH}$ and ADH enzyme activity.

\section{Biochemical assays}

Groups of 10 males (five replicates) were homogenized in $2 \mathrm{ml}$ cold homogenization buffer $(0.05 \mathrm{~m}$ glycine$\mathrm{NaOH}, 1 \mathrm{~mm}$ EDTA, pH 9.5). A sample of $0.025 \mathrm{ml}$ was taken and stored at $-20^{\circ} \mathrm{C}$ for the assay of triglycerides. The homogenates were centrifuged for $2 \mathrm{~min}$ at $11000 \mathrm{~g}$. To assay protein, $0.05 \mathrm{ml}$ supernate was stored at $-20^{\circ} \mathrm{C}$. The remaining supernate was stored at $0^{\circ} \mathrm{C}$ for immediate assay of $\alpha \mathrm{GPDH}$ and $\mathrm{ADH}$. Five replicates were assayed in duplo for each type. The final results (see tables) might have less than five replicates, because some replicates were lost during the assays.

Protein. This was assayed according to Bradford (1976). using the Biorad protein assay kit. To $0.05 \mathrm{ml}$ defrosted homogenate, $2.5 \mathrm{ml}$ reagent was added. After $20 \mathrm{~min}$ the extinction was measured at $590 \mathrm{~nm}$. The total protein content was calculated in micrograms using BSA as a standard.

Triglycerides. These were assayed using a modification of the enzymatic procedure described by Clark \& Gellman (1985). They found a good correlation between enzymatic triglyceride determination and the determination of total lipids by extraction. In the enzymatic procedure triglycerides were hydrolysed and the released glycerol quantified enzymatically (Bucolo \& David, 1973). The reagents were obtained from Sigma as Kit 334-UV and consisted of reagents A and $\mathrm{B}$. To the defrosted sample of $0.025 \mathrm{ml}$ homo- genate, $1.225 \mathrm{ml}$ reagent $\mathrm{A}$ was added. This was incubated at $35^{\circ} \mathrm{C}$ for $5 \mathrm{~min}$, centrifuged for $2 \mathrm{~min}$ at $11000 \mathrm{~g}$, and placed at $30^{\circ} \mathrm{C}$ for $3 \mathrm{~min}$. After reading $\mathrm{OD}_{590}, 0.025 \mathrm{ml}$ reagent $\mathrm{B}$ was added. The $\mathrm{OD}_{590}$ was read again after exactly $5 \mathrm{~min}$ at $30^{\circ} \mathrm{C}$. Triglycerides were calculated in micrograms using a triglyceride standard (Sigma 336-300).

$\alpha G P D H$ enzyme activity. This was measured using a modification of the procedure described by Rechsteiner (1970). To $0.85 \mathrm{ml}$ buffer $(0.05 \mathrm{M}$ glycine$\mathrm{NaOH}, 1 \mathrm{~mm}$ EDTA, $\mathrm{pH} 9.5)$ at $30^{\circ} \mathrm{C}, 0.05 \mathrm{ml}$ homogenate was added, followed by $0.1 \mathrm{ml}$ reagent buffer of $30^{\circ} \mathrm{C}$. The reagent consisted of glycine- $\mathrm{NaOH}$ buffer (see above) containing $\mathrm{NAD}^{+}$and $\mathrm{DL}^{-} \alpha$-glycerophosphate. The final concentration was $5 \mathrm{~mm} \mathrm{NAD}^{+}$and $10 \mathrm{~mm} \alpha$-glycerophosphate. The reaction rate was measured after $30 \mathrm{~s}$ during $90 \mathrm{~s}$ at $30^{\circ} \mathrm{C}$ and $340 \mathrm{~nm}$ (nine readings) in a Labsystems Chemistry Analyser FP401.

ADH enzyme activity. This was measured following the same procedure as for $\alpha \mathrm{GPDH}$. Isopropanol was used instead of $\alpha$-glycerophosphate, at a final concentration of $200 \mathrm{~mm}$.

\section{Statistical analysis}

ANOVA was performed to test the effects of $A d h$ genotype, $\alpha G p d h$ genotype and temperature. The reciprocal crosses were taken together. Where the ANOVA indicated significant differences, the data are shown in figures. Tukey's test for multiple comparisons was performed on groups of three temperatures or three genotypes with a level of significancy of 5 per cent; significant differences are indicated in the figures. In some cases (indicated in the results) data were standardized for temperature or genotype differences by subtracting the mean value per temperature or genotype from each replicate of that particular temperature or genotype.

\section{Results}

Only male data were analysed because females are more variable in weight and biochemical traits as there is variation in the number of eggs an individual female is carrying. Furthermore, ANOVA with respect to differences in developmental time between the sexes only showed a main effect of sex, and interaction between sex and temperature: females developed faster than males at all temperatures, although to a varying extent. No interactions were observed between sex and genotype. 


\section{Egg to adult developmental time}

ANOVA for the effects of $A d h$ genotype, $\alpha G p d h$ genotype and temperature on developmental time (Table 2) showed significant variation for all main effects and interactions. Developmental time was negatively correlated with rearing temperature (Fig. 1a). Figure 1b and $\mathrm{c}$ show the developmental time of $A d h$ and $\alpha G p d h$ genotypes at different temperatures. Figure $1 \mathrm{~d}$ and e show the interactions between $A d h$ and $\alpha G p d h$ genotypes at different temperatures.

At all rearing temperatures $A d h^{\mathrm{FF}}$ developed significantly faster than $A d h^{\mathrm{SS}}$, and $A d h^{\mathrm{FS}}$ was intermediate (Fig. 1b). This general picture of developmental rate differences between Adh genotypes is only slightly affected by interactions with temperature (Fig. 1c) or $a G p d h$ genotype (Fig. 1d). Figure 1e shows the interaction of $A d h$ genotype with $a G p d h$ genotype and temperature: at $29^{\circ} \mathrm{C} A d h^{\mathrm{FF}}$ developed significantly faster than $A d h^{S S}$ within all three $\alpha G p d h$ genotypes, at $25^{\circ} \mathrm{C}$ only within $\alpha G p d h^{\mathrm{FS}}$ and $\alpha G p d h^{\mathrm{SS}}$ were differences between $A d h$ genotypes significant, at $20^{\circ} \mathrm{C}$ only within $\alpha G p d h^{\mathrm{FS}}$ were significant differences in the developmental time of $A d h$ genotypes found. Notwithstanding significant interactions the results show that $A d h^{\mathrm{FF}}$ develops faster than $A d h^{\mathrm{SS}}$, while the heterozygote is intermediate.

$\alpha G p d h^{\mathrm{FF}}$ developed more slowly than $\alpha G p d h^{\mathrm{FS}}$ and $\alpha G p d h^{\text {SS }}$ (Fig. 1b), although differences were not significant at $29^{\circ} \mathrm{C}$ (Fig. 1c). Differences in developmental time between $\alpha G p d h$ genotypes showed a clear pattern of interaction with $A d h$ genotype and temperature (Fig. 1e). Significant differences between $\alpha G p d h$ genotypes were found at $20^{\circ} \mathrm{C}$ within all $A d h$ genotypes, and at $25^{\circ} \mathrm{C}$ only within $A d h^{\mathrm{FF}}$ and $A d h^{\mathrm{FS}}$. At $25^{\circ} \mathrm{C}$ the $A d h^{\mathrm{FS}}$ genotypes did not follow the general picture in that $\alpha G p d h^{\mathrm{FF}}$ and $\alpha G p d h^{\mathrm{SS}}$ were both slower than $\alpha G p d h^{\mathrm{FS}}$. At $29^{\circ} \mathrm{C}$ only within $A d h^{\mathrm{FF}}$ were significant differences found between $\alpha G p d h$ genotypes.

\section{Adult weight}

ANOVA for the effects of $A d h$ genotype, $a G p d h$ genotype and temperature on adult weight (Table 3 ) showed significant variation for all main effects, the interaction between $A d h$ and $\alpha G p d h$ and the interaction between $\alpha G p d h$ and temperature. Adult weight was negatively correlated with rearing temperature (Fig. 2a). Figure 2b and c show the weight of $A d h$ and $\alpha G p d h$ genotypes at 20,25 and $29^{\circ} \mathrm{C}$. $A d h^{\mathrm{FS}}$ was significantly heavier than $A d h^{\mathrm{FF}}$ and $A d h^{\mathrm{Ss}}$ (Fig. 2b). No interaction was observed between the $A d h$ genotype and temperature. The general picture of weight differences between $A d h$ genotypes is only slightly affected by interaction with the $\alpha G p d h$ genotype (Fig. $2 \mathrm{~d}$ ). The $\alpha G p d h$ genotype interacted with temperature (Fig. $2 \mathrm{c}$ ): at $20^{\circ} \mathrm{C}$ there were no significant differences, at $25^{\circ} \mathrm{C}$ $\alpha G p d h^{\mathrm{FF}}$ was significantly lighter than $\alpha G p d h^{\mathrm{ss}}$, and at $29^{\circ} \mathrm{C} a G p d h^{\mathrm{FF}}$ was significantly lighter than $\alpha G p d h^{\mathrm{FS}}$. The $\alpha G p d h$ genotypes (Fig. 2d) did not differ significantly within $A d h^{\mathrm{FF}}$ and $A d h^{\mathrm{FS}}$ genotypes but within $A d h^{\mathrm{SS}}$ genotypes $\alpha G p d h^{\mathrm{SS}}$ was significantly heavier than $\alpha G p d h^{\mathrm{FF}}$, with $\alpha G p d h^{\mathrm{FS}}$ being intermediate.

\section{Protein content}

ANOVA for the effects of Adh genotype, $\alpha G p d h$ genotype and temperature on protein content (Table 4) showed significant variation for $A d h$ genotype and interaction between $A d h$ genotype and temperature. Figure 3 shows the protein content of $A d h$ genotypes

Table 2 ANOVA for developmental time (hours) of males of different $A d h$ and $a G p d h$ genotypes reared at different temperatures

\begin{tabular}{lrrrrr}
\hline Source & \multicolumn{1}{c}{ SS } & d.f. & \multicolumn{1}{c}{ MS } & $F$ & $P<$ \\
\hline Adh genotype $(a)$ & 345 & 2 & 172 & 44 & 0.001 \\
aGpdh genotype $(g)$ & 191 & 2 & 96 & 24 & 0.001 \\
Temperature $(t)$ & 1145888 & 2 & 572944 & 145788 & 0.001 \\
$a \times g$ & 96 & 4 & 24 & 6 & 0.001 \\
$a \times t$ & 69 & 4 & 17 & 4 & 0.01 \\
$g \times t$ & 93 & 4 & 23 & 6 & 0.001 \\
$a \times g \times t$ & 165 & 8 & 21 & 5 & 0.001 \\
Explained & 1146847 & 26 & 44109 & 11224 & 0.001 \\
Residual & 955 & 243 & 4 & & \\
Total & 1147802 & 269 & 4267 & & \\
\hline
\end{tabular}


(a) All genotypes combined.

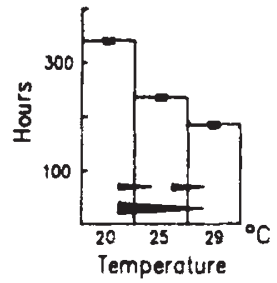

(c) Single locus genotypes.

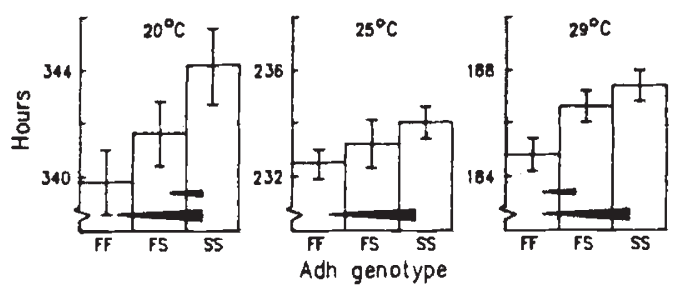

(d) Two loci genotypes,temperatures combined.
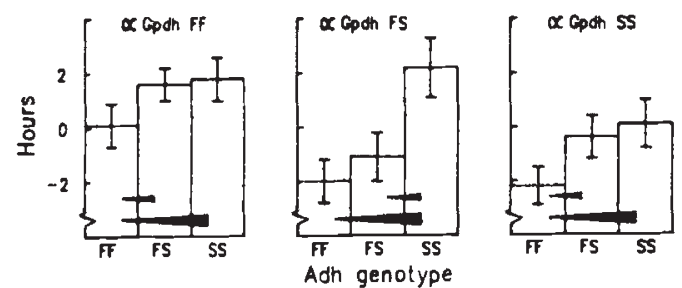

(e) Two loci genotypes
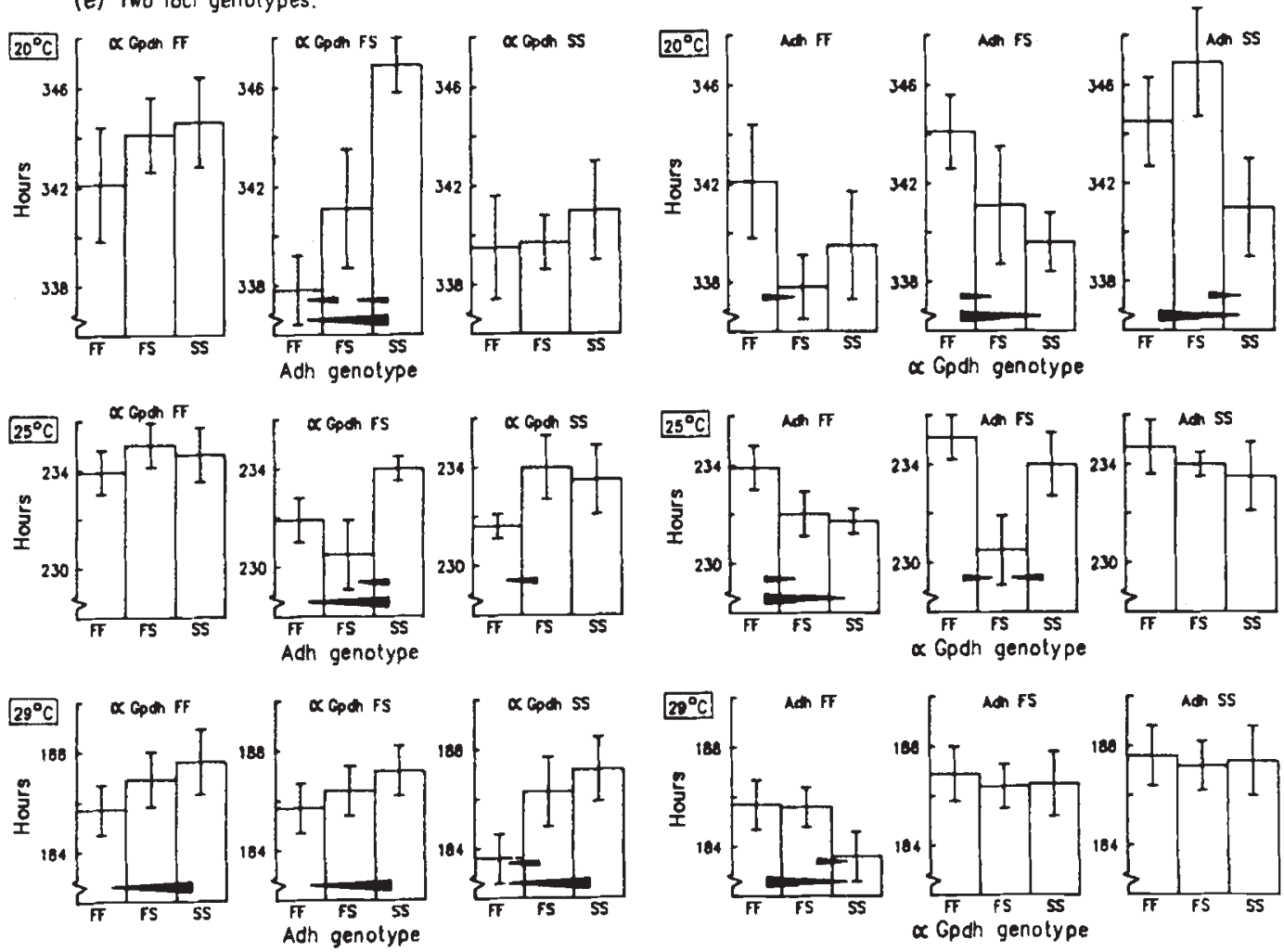

Fig. 1 Egg-to-adult developmental time (h) of males. Vertical bars indicate 95 per cent confidence intervals. Arrows indicate significant differences with Tukey's test $(P<0.05)$. The data are standardized for temperature differences for Fig. $1 \mathrm{~b}$ and d, these figures show the deviation from the mean of all genotypes per temperature. 
Table 3 ANOVA for body weight (mg) of adult males of different $A d h$ and $\alpha G p d h$ genotypes reared at different temperatures

\begin{tabular}{llrlrl}
\hline Source & SS & d.f. & \multicolumn{1}{l}{ MS } & \multicolumn{1}{l}{$F$} & $P<$ \\
\hline Adh genotype $(a)$ & 0.018 & 2 & 0.009 & 25.3 & 0.001 \\
a Gpdh genotype $(g)$ & 0.003 & 2 & 0.001 & 3.6 & 0.05 \\
Temperature $(t)$ & 0.671 & 2 & 0.335 & 967.6 & 0.001 \\
$a \times g$ & 0.011 & 4 & 0.003 & 7.6 & 0.001 \\
$a \times t$ & 0.001 & 4 & 0.000 & 0.8 & $\mathrm{~ns}$ \\
$g \times t$ & 0.006 & 4 & 0.001 & 4.1 & 0.01 \\
$a \times g \times t$ & 0.004 & 8 & 0.001 & 1.5 & $\mathrm{~ns}$ \\
Explained & 0.712 & 26 & 0.027 & 79.0 & 0.001 \\
Residual & 0.084 & 243 & 0.000 & & \\
Total & 0.796 & 269 & 0.003 & & \\
\hline
\end{tabular}

(a) All genotypes

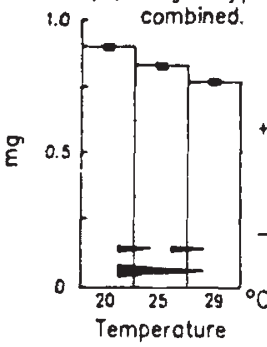

(b) Single locus genotypes temperotures combined.
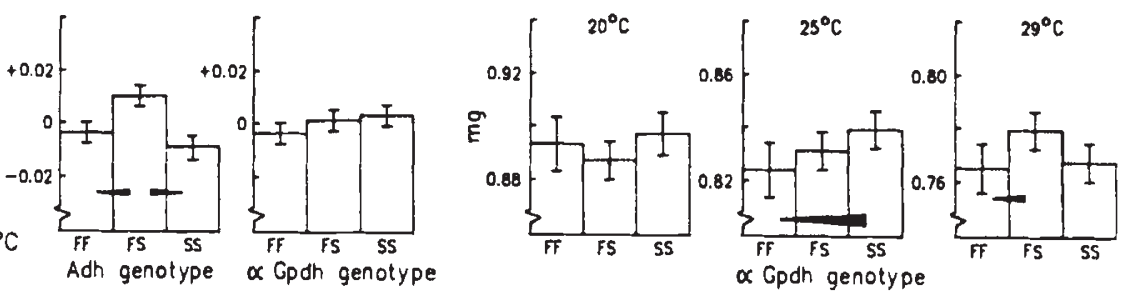

(d) Two loci genotypes, temperotures combined.
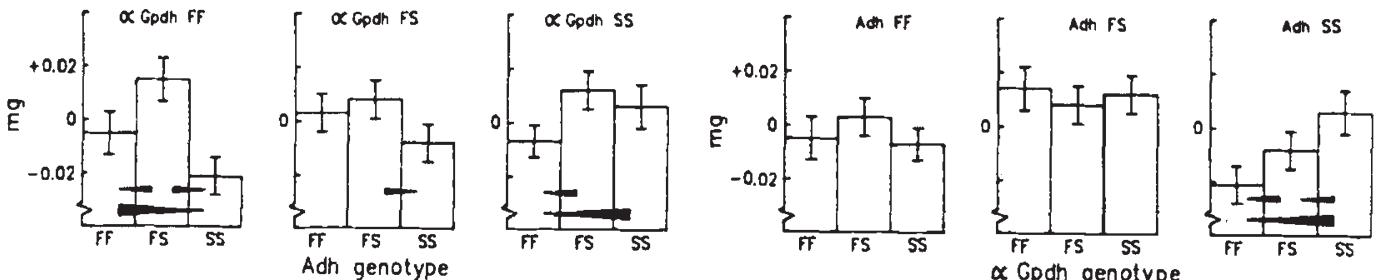

Fig. 2 Body weight of adult males (mg/individual). Vertical bars indicate 95 per cent confidence intervals. Arrows indicate significant differences with Tukey's test $(P<0.05)$. The data are standardized for temperature differences for Fig. $2 \mathrm{~b}$ and d.

Table 4 ANOVA for protein content ( $\mu$ g protein/mg body weight) of adult males of different $A d h$ and $\alpha G p d h$ genotypes reared at different temperatures

\begin{tabular}{lrrrrl}
\hline Source & \multicolumn{1}{c}{ SS } & d.f. & \multicolumn{1}{c}{ MS } & \multicolumn{1}{l}{$F$} & $P<$ \\
\hline Adh genotype $(a)$ & 367.0 & 2 & 183.5 & 19.9 & 0.001 \\
aGpdh genotype $(g)$ & 27.8 & 2 & 13.9 & 1.5 & $\mathrm{~ns}$ \\
Temperature $(t)$ & 5.7 & 2 & 2.9 & 0.3 & $\mathrm{~ns}$ \\
$a \times g$ & 39.7 & 4 & 9.9 & 1.1 & $\mathrm{~ns}$ \\
$a \times t$ & 224.1 & 4 & 56.0 & 6.1 & 0.001 \\
$g \times t$ & 76.5 & 4 & 19.1 & 2.1 & $\mathrm{~ns}$ \\
$a \times g \times t$ & 107.3 & 8 & 13.4 & 1.5 & $\mathrm{~ns}$ \\
Explained & 847.9 & 26 & 32.6 & 3.5 & 0.001 \\
Residual & 1698.2 & 184 & 9.2 & & \\
Total & 2546.1 & 210 & 12.1 & & \\
\hline
\end{tabular}


at 20,25 and $29^{\circ} \mathrm{C}$. Combined $A d h^{\text {ss }}$ had a significant lower protein content for all temperatures than $A d h^{\mathrm{FF}}$ and $A d h^{\mathrm{FS}}$ (Fig. 3a), this effect was more extreme at higher temperatures (Fig. 3b).

\section{Triglycerides}

ANOVA for the effects of $A d h$ genotype, $\alpha G p d h$ genotype and temperature on adult triglycerides content (Table 5) showed significant variation for all main effects and the interaction between $A d h$ and $\alpha G p d h$. The triglyceride content was equal at 20 and 25 , but significantly lower at $29^{\circ} \mathrm{C}$ (Fig. 4a). $A d h^{\mathrm{FS}}$ had a lower triglyceride content than $A d h^{\mathrm{SS}}$ (Fig. 4b). $\alpha G p d h^{\mathrm{FS}}$ had a higher triglyceride content than $\alpha G p d h^{\mathrm{FF}}$ and $\alpha G p d h^{\mathrm{sS}}$ (Fig. 4b). Interactions between $A d h$ and $\alpha G p d h$ are shown in Fig. 4c. There were no significant differences within $\alpha G p d h^{\mathrm{FF}}$ and $\alpha G p d h^{\mathrm{FS}}$ in the triglyceride content between the $A d h$ genotypes. $A d h^{\text {sS }}$ had the highest triglycerides content within $\alpha G p d h^{\text {ss }}$ genotypes. Differences between $\alpha G p d h$ genotypes vary only slightly within $A d h$ genotypes.

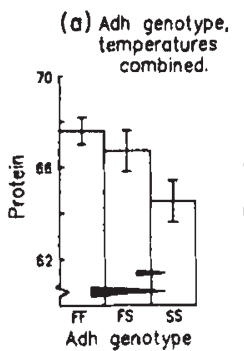

\section{(b) Adh genotype.}
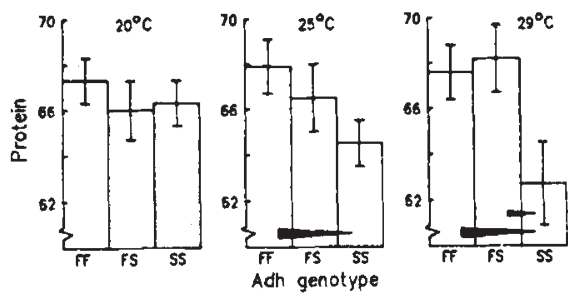

Fig. 3 Protein content of adult males ( $\mu$ g protein $\mathrm{mg}^{-1}$ bodyweight). Vertical bars indicate 95 per cent confidence intervals. Arrows indicate significant differences with Tukey's test $(P<0.05)$.

\section{ADH enzyme activity}

ANOVA for the effects of $A d h$ and $\alpha G p d h$ genotype and temperature on ADH activity (Table 6) revealed significant variation for all three main effects and an interaction between $A d h$ and $\alpha G p d h$. ADH activity at $20^{\circ} \mathrm{C}$ was slightly lower than at 25 and $29^{\circ} \mathrm{C}$ (Fig. 5a).

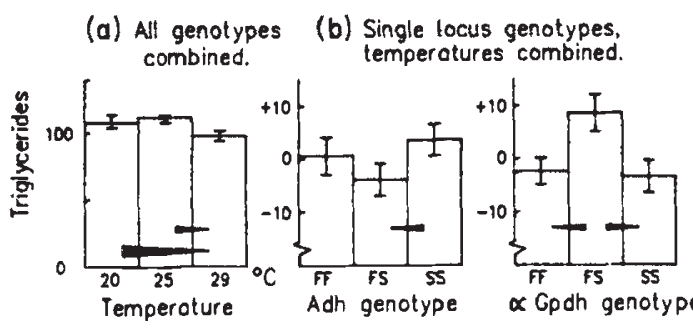

(c) Two loci genotypes,temperatures combined.
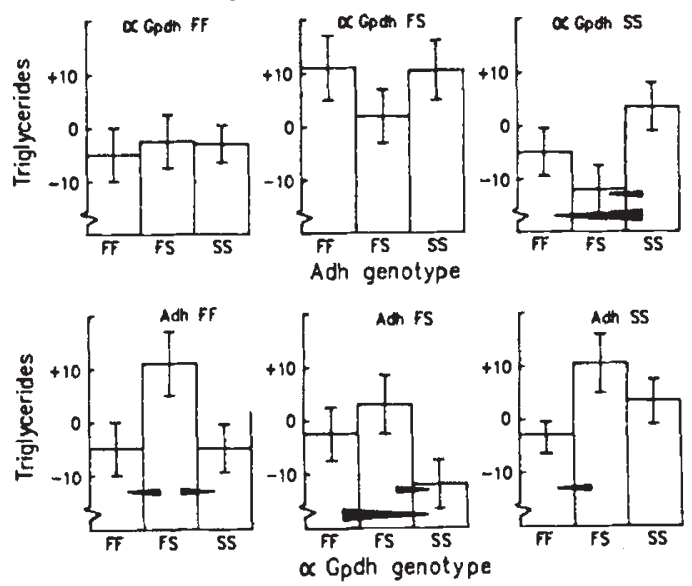

Fig. 4 Triglyceride content of adult males $(\mu \mathrm{g}$ triglycerides $\mathrm{mg}^{-1}$ bodyweight). Vertical bars indicate 95 per cent confidence intervals. Arrows indicate significant differences with Tukey's test $(P<0.05)$. The data are standardized for temperature differences for Fig. $4 \mathrm{~b}$ and $\mathrm{c}$

Table 5 ANOVA for triglycerides content ( $\mu$ g triglycerides/mg body weight) of adult males of different $A d h$ and $\alpha G p d h$ genotypes reared at different temperatures

\begin{tabular}{lcrrrl}
\hline Source & \multicolumn{1}{l}{ SS } & d.f. & \multicolumn{1}{c}{ MS } & \multicolumn{1}{c}{$F$} & $P<$ \\
\hline Adh genotype $(a)$ & 1986 & 2 & 993 & 7.7 & 0.001 \\
a Gpdh genotype $(g)$ & 7003 & 2 & 3502 & 27.1 & 0.001 \\
Temperature $(t)$ & 8243 & 2 & 4122 & 32.0 & 0.001 \\
$a \times g$ & 1779 & 4 & 445 & 3.4 & 0.01 \\
$a \times t$ & 1049 & 4 & 262 & 2.0 & $\mathrm{~ns}$ \\
$g \times t$ & 182 & 4 & 45 & 0.4 & $\mathrm{~ns}$ \\
$a \times g \times t$ & 685 & 8 & 86 & 0.7 & $\mathrm{~ns}$ \\
Explained & 21057 & 26 & 810 & 6.3 & 0.001 \\
Residual & 23735 & 184 & 129 & & \\
Total & 44791 & 210 & 213 & & \\
\hline
\end{tabular}


Table 6 ANOVA for ADH enzyme activity (nmol NADH $\min ^{-1} \mu \mathrm{g}^{-1}$ protein) of adult males of different $A d h$ and $\alpha G p d h$ genotypes reared at different temperatures

\begin{tabular}{lrrlrl}
\hline Source & \multicolumn{1}{l}{ SS } & d.f. & MS & \multicolumn{1}{l}{$F$} & $P<$ \\
\hline Adh genotype $(a)$ & 14.98 & 2 & 7.490 & 2223.5 & 0.001 \\
$a G p d h$ genotype $(g)$ & 0.38 & 2 & 0.188 & 55.8 & 0.001 \\
Temperature $(t)$ & 0.06 & 2 & 0.031 & 9.2 & 0.001 \\
$a \times g$ & 0.15 & 4 & 0.038 & 11.3 & 0.001 \\
$a \times t$ & 0.03 & 4 & 0.008 & 2.4 & $\mathrm{~ns}$ \\
$g \times t$ & 0.01 & 4 & 0.001 & 0.3 & $\mathrm{~ns}$ \\
$a \times g \times t$ & 0.4 & 8 & 0.004 & 1.3 & $\mathrm{~ns}$ \\
Explained & 15.51 & 26 & 0.597 & 177.1 & 0.001 \\
Residual & 0.58 & 173 & 0.003 & & \\
Total & 16.10 & 199 & 0.081 & & \\
\hline
\end{tabular}

(a) All genotypes

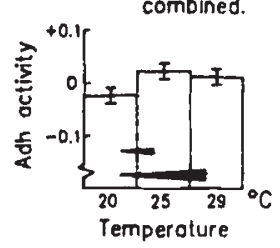

(b) Two loci genotypes.temperatures combined.
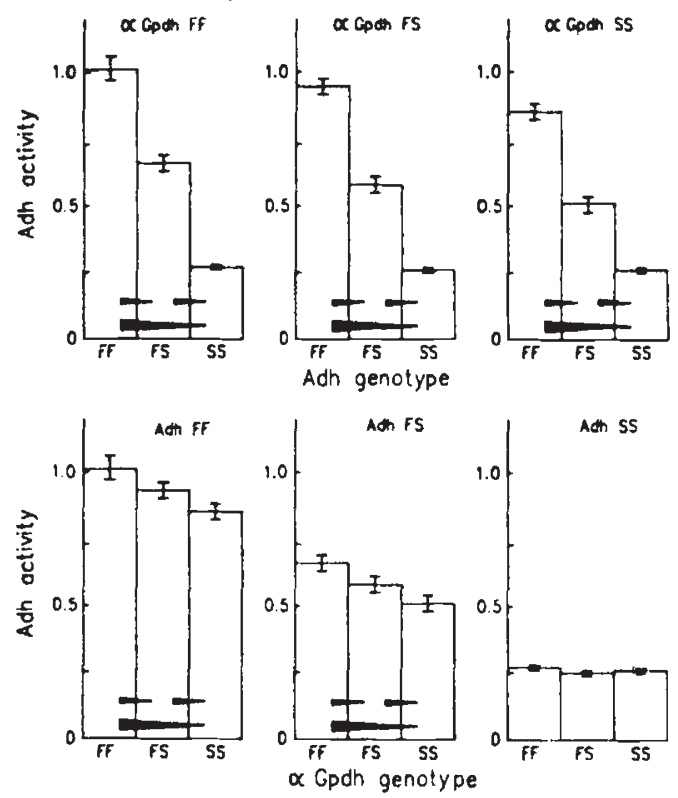

Fig. 5 ADH enzyme activity of adult males (nmol NADH $\mathrm{min}^{-1} \mu \mathrm{g}^{-1}$ protein). Vertical bars indicate 95 per cent confidence intervals. Arrows indicate significant differences with Tukey's test $(P<0.05)$. The data are standardized for $A d h$ genotype differences for Fig. 5a

The interaction between $A d h$ and $\alpha G p d h$ is shown in Fig. 5b. The ADH activity of $A d h^{\mathrm{FF}}$ was higher than $A d h^{\mathrm{sS}}$ within all $\alpha G p d h$ genotypes, with $A d h^{\mathrm{FS}}$ being intermediate. There were significant differences between $\alpha G p d h$ genotypes within $A d h^{\mathrm{FF}}$ and $A d h^{\mathrm{FS}}$ genotypes: $\alpha G p d h^{\mathrm{FF}}$ had higher $\mathrm{ADH}$ activity than $\alpha G p d h^{\mathrm{SS}}$, with $\alpha G p d h^{\mathrm{FS}}$ being intermediate. The differences in ADH enzyme activity of identical $A d h$ genotypes between $\alpha G p d h$ genotypes were small compared to differences between $A d h$ genotypes.

\section{$\alpha G P D H$ enzyme activity}

ANOVA for the effects of $A d h$ and $\alpha G p d h$ genotype and temperature on $\alpha$ GPDH enzyme activity (Table 7) revealed a significant variation for temperature, $A d h$ genotype and the interaction between $A d h$ and $\alpha G p d h$. $\alpha$ GPDH activity at $29^{\circ} \mathrm{C}$ was slightly lower than at 25 and $20^{\circ} \mathrm{C}$ (Fig. 6a). An interaction between the $A d h$ and $\alpha G p d h$ genotypes is shown in Fig. 6b. $A d h^{\mathrm{Ss}} \alpha G p d h^{\mathrm{FF}}$ had significantly higher activity than $A d h^{\mathrm{sS}} \alpha G p d h^{\mathrm{FS}}$ and $A d h^{\mathrm{ss}} \alpha G p d h^{\mathrm{ss}}$. The differences in $\alpha$ GPDH enzyme activity were very small compared to the differences in ADH enzyme activity.

\section{Correlation between characters}

Table 8 shows the correlations between the studied traits, calculated from genotype means standardized for temperature differences. Two trends can be derived from these data.

1 There is a significant positive correlation between weight, protein content (per individual) and $\alpha$ GPDH enzyme activity (per individual). These variables are not correlated if protein content is calculated per milligram of bodyweight and the $\alpha$ GPDH enzyme activity is calculated per microgram of protein (Table 8, below diagonal), so these correlations may be an effect of size: heavier genotypes have proportionally more protein and $\alpha$ GPDH enzyme activity.

2 There is a significant negative correlation between developmental time on the one hand and ADH and 
Table 7 ANOVA for $\alpha$ GPDH enzyme activity (nmol NADH $\min ^{-1} \mu \mathrm{g}^{-1}$ protein) of adult males of different $A d h$ and $\alpha G p d h$ genotypes reared at different temperatures

\begin{tabular}{llrlll}
\hline Source & SS & d.f. & MS & $F$ & $P<$ \\
\hline Adh genotype $(a)$ & 0.013 & 2 & 0.006 & 3.2 & 0.05 \\
$\begin{array}{l}\alpha G p d h \text { genotype }(g) \\
\text { Temperature }(t)\end{array}$ & 0.009 & 2 & 0.005 & 2.3 & ns \\
$a \times g$ & 0.027 & 2 & 0.014 & 6.9 & 0.001 \\
$a \times t$ & 0.077 & 4 & 0.019 & 9.8 & 0.001 \\
$g \times t$ & 0.017 & 4 & 0.004 & 2.1 & ns \\
$a \times g \times t$ & 0.005 & 4 & 0.001 & 0.7 & ns \\
Explained & 0.020 & 8 & 0.003 & 1.3 & ns \\
Residual & 0.169 & 26 & 0.006 & 3.3 & 0.001 \\
Total & 0.360 & 183 & 0.002 & & \\
\hline
\end{tabular}

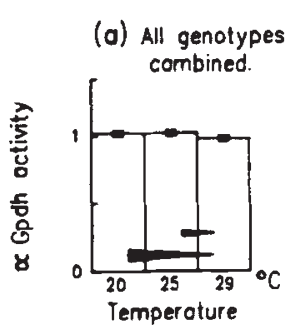

(b) Two loci genotypes, temperotures combined.
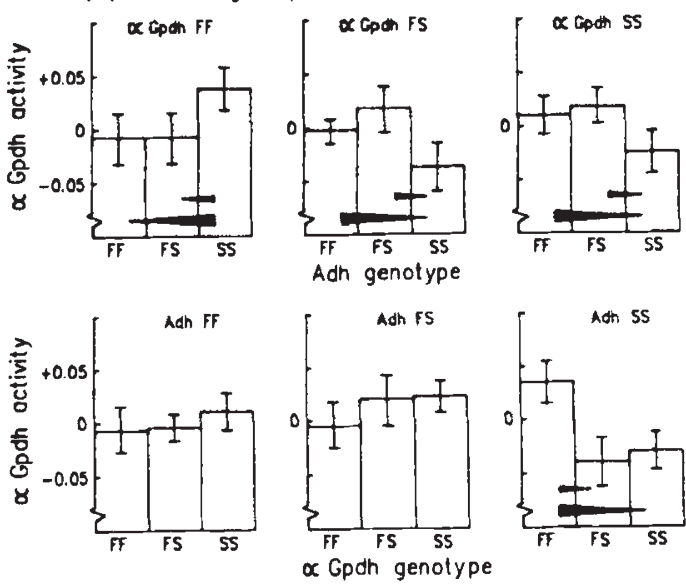

Fig. $6 \alpha$ GPDH enzyme activity of adult males ( $\mathrm{nmol}$ NADH $\min ^{-1} \mu \mathrm{g}^{-1}$ protein). Vertical bars indicate 95 per cent confidence intervals. Arrows indicate significant differences with Tukey's test $(P<0.05)$. The data are standardized for temperature differences for Fig. $6 \mathrm{~b}$.

$\alpha$ GPDH enzyme activity on the other. The same trend, although not significant, is found for protein and weight in relation to developmental time. We therefore found no trade-off between developmental time and these traits. Triglyceride content, however, does not follow this trend, and is not correlated with developmental time or weight.
ADH enzyme activity is significantly negatively correlated with developmental time. Combining this with the data in Figs $1 \mathrm{~b}$ and $5 \mathrm{~b}$, it can be concluded that the negative correlation between ADH enzyme activity and developmental time coincides with $A d h$ genotype. Within the Adh genotypes, however, the correlation between ADH enzyme activity and developmental time becomes positive, taken the data standardized for Adh genotype differences (Table 8, ADHst). Combining this with the data in Figs $1 \mathrm{~b}$ and $5 \mathrm{~b}$, it appears that the positive correlation between ADH enzyme activity and developmental time within Adh genotypes and temperatures coincides with the $\alpha G p d h$ genotype: $\alpha G p d h^{\mathrm{FF}}$ have higher ADH enzyme activity and longer developmental time than $\alpha G p d h^{\text {ss }}$ genotypes, with $\alpha G p d h^{\mathrm{FS}}$ genotypes being intermediate.

\section{Discussion}

The developmental rate was affected by both the $A d h$ and the $\alpha G p d h$ genotype. $A d h^{\mathrm{FF}}$ developed faster than $A d h^{\mathrm{ss}}$, and $A d h^{\mathrm{FS}}$ was intermediate. Literature on the developmental rate of $A d h$ genotypes comes from (i) selection experiments for developmental rate in polymorphic populations (Van Delden \& Kamping, 1979; Cavener, 1983; Knibb et al., 1987), (ii) determination of genotype frequencies in fast and slow developing groups within polymorphic populations (Van Delden \& Kamping, 1979; Marinković et. al., 1987), and (iii) measurement of developmental rate of homozygous strains (Kerver \& Van Delden, 1985; Kohane \& Parsons, 1986; Izquierdo \& Rubio, 1989). Although some of these studies revealed no differences in the rate of development between Adh genotypes, most studies indicated that $A d h^{\mathrm{FF}}$ develops faster than 
Table 8 Coefficients of correlation $(r)$ between developmental time, adult body weight, protein content and triglycerides content and ADH and $\alpha$ GPDH enzyme activity, calculated from genotype means $(n=27)$ standardized for temperature differences. Above the diagonal protein, triglycerides, $\mathrm{ADH}$ and $\alpha \mathrm{GPDH}$ are expressed per individual, below the diagonal protein and triglycerides are expressed per milligram of bodyweight, and ADH and $\alpha$ GPDH per microgram of protein. For the variable ADHst data are standardized for temperature and $A d h$ genotype differences

\begin{tabular}{llccccrr}
\hline & $\begin{array}{l}\text { Developmental } \\
\text { time }\end{array}$ & Weight & Protein & Triglyceride & $\alpha$ GPDH & ADH & ADHst \\
\hline Developmental time & & -0.21 & -0.32 & 0.00 & $-0.43^{*}$ & $-0.52^{* *}$ & $0.41^{*}$ \\
Weight & -0.21 & & $0.62^{* *}$ & 0.14 & $0.56^{* *}$ & 0.16 & 0.23 \\
Protein & -0.27 & 0.27 & & 0.02 & $0.79^{* *}$ & $0.57^{* *}$ & 0.08 \\
Triglyceride & 0.05 & -0.05 & -0.11 & & -0.27 & -0.10 & 0.22 \\
$\alpha$ GPDH & -0.24 & -0.03 & -0.26 & $-0.47^{*}$ & & $0.58^{* *}$ & -0.15 \\
ADH & $-0.52^{* *}$ & 0.14 & $0.61^{* *}$ & -0.14 & 0.12 & & \\
ADHst & $0.44^{*}$ & 0.13 & -0.04 & 0.13 & -0.14 & & \\
\hline
\end{tabular}

*Significant at 0.05 level.

** Significant at 0.01 level.

$A d h^{\mathrm{SS}}$, with $A d h^{\mathrm{FS}}$ being intermediate or equal to one of the homozygous genotypes. Our results are thus well in agreement with these findings. Kohane \& Parsons (1986) found no interaction between the rate of development of $A d h$ genotypes and temperature.

$\alpha G p d h^{\mathrm{FF}}$ developed more slowly than $\alpha G p d h^{\mathrm{FS}}$ and $\alpha G p d h^{\text {ss }}$. The literature on developmental rate differences between $\alpha G p d h$ genotypes is ambiguous. Selection for developmental rate (Cavener, 1983) indicated a relative faster development of $\alpha G p d h^{\mathrm{FF}}$. The determination of genotype frequencies in fast and slow developing groups of a polymorphic population (Marinković et al., 1987) also indicated a relative faster development of $\alpha G p d h^{\mathrm{FF}}$. Measurement of the developmental rate of homozygous strains by Izquierdo \& Rubio (1989), however, showed a relative faster development of $\alpha G p d h^{\text {ss }}$. Measurement of the developmental rate at different temperatures (Barnes $e t$ al., 1989) indicated a relative faster developmental rate of $\alpha G p d h^{\text {sS }}$ at low temperature. So the data on homozygous strains are in agreement with our data, in contrast to the data on polymorphic populations. This contradiction may be explained by density-dependent effects. Both experiments with polymorphic populations (Cavener, 1983; Marinković et al., 1987) were performed under high-density conditions, as can be concluded from the fact that in both experiments adult eclosion was spread over at least 10 days. Measurements on homozygous strains-(Izquierdo \& Rubio, 1989; Barnes et al., 1989; our paper) were performed at rather low densities: So $\alpha G p d h^{\mathrm{sS}}$ may have a relative faster development at low and $\alpha G p d h^{\mathrm{FF}}$ at high densities. Density-dependent effects for the viability of $\alpha G p d h$ genotypes are known from the experiments of Charles-Palabost (1982) who found higher viability of the $\alpha G p d h^{\mathrm{FF}}$ genotypes than $\alpha G p d h^{\text {ss }}$ genotypes under low density conditions, but a reversal at high density.

The interaction between the effects of $\alpha G p d h$ genotypes and rearing temperature on developmental rate $\left(\alpha G p d h^{\mathrm{FF}}\right.$ genotypes developed more slowly than $\alpha G p d h^{\mathrm{FS}}$ and $\alpha G p d h^{\mathrm{SS}}$ genotypes at 20 and 25 , but not at $29^{\circ} \mathrm{C}$ ) is in agreement with the data of Barnes et al. (1989). Interaction between the effects of $A d h$ and $\alpha$ Gpdh genotype on developmental time (Fig. 1d) chiefly concerned the relative position of the heterozygous genotypes, in some cases they were equal to the one homozygous genotype, in other cases they were equal to the other homozygous genotype. The interaction between the $A d h$ and $\alpha G p d h$ genotype and temperature (Fig. 1e) is very interesting. Significant differences between $\alpha G p d h$ genotypes were found at $20^{\circ} \mathrm{C}$ within all $A d h$ genotypes, at $25^{\circ} \mathrm{C}$ only within $A d h^{\mathrm{FF}}$ and $A d h^{\mathrm{FS}}$, and at $29^{\circ} \mathrm{C}$ only within $A d h^{\mathrm{FF}}$.

Is the correlation between developmental rate and $A d h$ and $\alpha G p d h$ genotype caused by differences in metabolic flux through pathways in which ADH and $\alpha \mathrm{GPDH}$ are involved? Allozymes can influence metabolic processes by differences in the amount or activity. We found that $A d h^{\mathrm{FF}}$ strains had a 3.5 time higher ADH activity than $A d h^{\text {SS }}$ strains. This difference is well known from the literature (see review by Chambers, 1988): in Drosophila melanogaster strains that carry the $A d h^{\mathrm{s}}$ allele generally have lower ADH activity levels than lines with $A d h^{\mathrm{F}}$ alleles, which is largely accounted for by differences in protein level. We found no differences in $\alpha$ GPDH enzyme activity between $\alpha G p d h$ genotypes. This is in agreement with the data of Laurie-Ahlberg (1985), who found that over a large number of strains the $\alpha \mathrm{GPDH}$ enzyme 
activity of $\alpha G p d h^{\text {sS }}$ genotypes on average was slightly higher than that of $\alpha G p d h^{\mathrm{FF}}$ strains, although there was a very broad overlap. We found only small interactions between the $A d h$ and $\alpha G p d h$ genotype for both $\mathrm{ADH}$ (Fig. 5b) and $\alpha$ GPDH (Fig. 6b) enzyme activity. As in vivo substrate concentrations are generally too low to saturate enzymes, $V_{\max }$ (essentially the enzyme activity as measured here) is not an appropriate description of in vivo enzyme activity, instead $V_{\max } / K_{\mathrm{m}}$ may be a better approximation (e.g. Middleton \& Kacser, 1983). Such calculations for ADH still result in a higher enzyme activity of $A d h^{\mathrm{FF}}$ compared with $A d h^{\text {ss }}$, independent from the temperature (Alahiotis, 1982; McElfresh \& McDonald, 1986; Heinstra et al., 1988 ). The enzyme activity differences for $\alpha \mathrm{GPDH}$ between the allozymes are not as clear as for $\mathrm{ADH}$, but a strong temperature effect is described (Miller et al., 1975; Alahiotis et al., 1977; McKechnie et al., 1981; not found by Bewley et al., 1984): the $K_{\mathrm{m}}$ (DHAP) between 20 and $30^{\circ} \mathrm{C}$ is constant for $\alpha G p d h^{\mathrm{FF}}$ but increases with temperature for ' $\alpha G p d h^{\mathrm{SS}}$ and $\alpha G p d h^{\mathrm{FS}}$. If we assume no substantial relative differences in $V_{\max }$, the in vivo enzyme activity of $\alpha G p d h^{\mathrm{FS}}$ and $\alpha G p d h^{\mathrm{SS}}$ might decrease, compared to $\alpha G p d h^{\mathrm{FF}}$, with increasing temperature. This relative increase of $\alpha \mathrm{GPDH}$ in vivo enzyme activity of $\alpha G p d h^{\mathrm{FF}}$ is correlated with our finding of a relative increase in the developmental rate of $\alpha G p d h^{\mathrm{FF}}$ with increasing temperature (Fig. 1c). This might indicate a positive correlation between $\alpha \mathrm{GPDH}$ enzyme activity and the developmental rate.

It has to be stressed that the observed developmental rate differences between genotypes are rather small: a maximum of 2 per cent. A selection experiment in our laboratory (B. J. Zwaan, in preparation) for fast and slow development in the same strain, Groningen 83 , revealed, after 10 generations of selection, a difference of 15 per cent between the fast and the slow selection lines. The relative small effect of $A d h$ and $\alpha G p d h$ is in agreement with the metabolic control theory (e.g. Hartl \& Clark, 1989) that predicts that metabolic flux differences, due to activity differences between allozymes, are very small because enzymes are embedded in a matrix of many other enzymes. Indeed, the metabolic pathways in which $\mathrm{ADH}$ and $\alpha \mathrm{GPDH}$ function are rather diffuse. Geer $e t$ al. (1985) found that ADH plays a role in the conversion of both ethanol and sucrose to lipids (fatty acids) in larvae of Drosophila melanogaster. Heinstra et al. (1990) showed that carbon atoms from ethanol are also incorporated in carbohydrates and amino acids. The oxidation of ethanol by $\mathrm{ADH}$ generates $\mathrm{NADH}$. $\alpha \mathrm{GPDH}$ plays an important role in the flight metabolism of adult Drosophila melanogaster in regenerating $\mathrm{NAD}^{+}$in concert with the mitochondrial $\alpha \mathrm{GPO}$ forming the ' $\alpha$ GPDH-shuttle' (O'Brien and MacIntyre, 1978). An analogous role of $\alpha \mathrm{GPDH}$ in the regulation of $\mathrm{NAD}^{+} / \mathrm{NADH}$ ratios in larval tissues is proposed by several authors (e.g. Rechsteiner, 1970; Geer et al., 1983). Further $\alpha$ GPDH converts dihydroxyacetone phosphate to glycerophosphate, a precursor for phospholipids and triglycerides (O'Brien and MacIntyre, 1978; Geer et al., 1983).

Heterozygote superiority was found for adult body weight $\left(A d h^{\mathrm{FS}}\right.$ genotypes were the heaviest) and triglyceride content $\left(\alpha G p d h^{\mathrm{FS}}\right.$ genotypes had the most triglycerides). Partridge (1988) found a correlation between body size and lifetime reproductive success in both males and females. Lipid content is related to resistance to starvation (David et al., 1983; Zwaan et al., 1991) and viability and fecundity (Clark, 1989). As heterozygote effects are supposed to play an important role in the maintenance of the polymorphism of both $A d h$ and $\alpha G p d h$ in nature (Bijlsma-Meeles \& Bijlsma, 1988; Chambers, 1988), our data fit well. We have planned further research on these traits.

The adaptive consequences of the developmental rate are rather complex. A fast rate of development will generally lead to a higher fitness. Parsons (1983), however, pointed out that there might be a difference between climates. In extreme climates (far from the equator) there is an advantage for the $r$-strategy, with a fast rate of development. Under more optimal conditions (near the equator) there is an advantage for the $K$ strategy, with a slow rate of development. In the light of this theory, our data on the developmental time of $A d h$ and $\alpha G p d h$ genotypes fit well with the world-wide cline of $A d h$ and $\alpha G p d h$ allele frequencies. $A d h^{\mathrm{s}}$ and $\alpha G p d h^{\mathrm{F}}$ frequencies are high near the equator (Oakeshott et al., 1982) and we found that these alleles are related to slow development, which provides an advantage in these regions. At higher latitudes $A d h^{\mathrm{F}}$ and $\alpha G p d h^{s}$ are more frequent (Oakeshott et al., 1982) and we found that these alleles are related to fast development, which also provides an advantage in these regions. Our data thus indicate that the developmental rate differences between the genotypes might be one of the underlying mechanisms for the allele frequency clines.

Furthermore, this study has shown that several differences occur among both $A d h$ and $\alpha G p d h$ genotypes for traits which may have adaptive consequences. In addition, an interaction between $A d h$ and $\alpha G p d h$ may occur. The differences observed, except $\mathrm{ADH}$ enzyme activity between $A d h$ genotypes, are generally very small; it is conceivable that under more stressful conditions than those applied in these experiments, these differences might be emphasized. 


\section{Acknowledgements}

The investigations were supported by the Foundation for Biological Research (BION), which is subsidized by The Netherlands Organization for Scientific Research (NWO; grant 811-436-104). We would like to thank A. Rumahloine and L. Hoeksema-Du Pui for assistance with electrophoresis and $\mathrm{H}$. Mulder for preparing the figures.

\section{References}

ALAhIOTIS, S. N. 1982. Adaptation of Drosophila enzymes to temperature. IV. Natural selection at the alcohol dehydrogenase locus. Genetica, 59, 81-87.

ALAHIOTIS, S. N., MILLER, S. AND BERGER, E. 1977. Natural selection at the $\alpha-G D H$ locus in Drosophila. Nature, 269, 144-145.

ANDERSON, P. R., KNIBB, W. R. AND OAKESHOTT, J. G. 1987. Observations on the extent and temporal stability of latitudinal clines for alcohol dehydrogenase allozymes and four chromosome inversions in Drosophila melanogaster. Genetica, 75, 81-88.

BARNES, P. T., HOLLAND, B. AND COURREGES, v. 1989. Genotypeby-environment and epistatic interactions in Drosophila melanogaster: the effects of $G p d h$ allozymes, genetic background and rearing temperature on larval developmental time and viability. Genetics, 122, 859-868.

BEWLEY, G. C., NIESEL, D. W. AND WILKINS, J. R. 1984. Purification and characterization of the naturally occurring allelic variants of sn-glycerol-3-phosphate dehydrogenase in Drosophila melanogaster. Comp. Biochem. Physiol., 79B, 23-32.

BIJLSMA-MEELES, E. AND BIJLSMA, R. 1988. The alcohol dehydrogenase polymorphism in Drosophila melanogaster: fitness measurements and predictions under conditions with no alcohol stress. Genetics, 120, 743-753.

BRADFORD, M. M. 1976. A rapid and sensitive method for the quantitation of microgram quantities of protein utilizing the principle of protein-dye binding. Anal. Biochem., 72, 248-254.

BUCOLO, G. AND DAVID, H. 1973. Quantitative determination of serum triglycerides by the use of enzymes. Clin. Chem., $19,476$.

CAVENER, D. R. 1983. The response of enzyme polymorphisms to developmental rate selection in Drosophila melanogaster. Genetics, 105, 105-113.

CAVENER, D. R. AND CLEGG, M. T. 1981. Multigenic response to ethanol in Drosophila melanogaster. Evolution, 35, 1-10.

Chambers, G. K. 1988. The Drosophila alcohol dehydrogenase gene-enzyme system. Adv. Genet., 25, 39-107.

CHARLES-PALABOST, L. 1982. Influence du milieu sur le maintien du polymorphisme de l' $\alpha$-glycérophosphate déshydrogénase chez Drosophila melanogaster. Arch. Zool. Exp. Gén., 122, 467-477.

CLARK, A. G. 1989. Causes and consequences of variation in energy storage in Drosophila melanogaster. Genetics, 123, 131-144.
Clark, A. G. AND Gellman, w. 1985. A rapid spectrophotometric assay of triglycerides in Drosophila. Dros. Inf. Serv., $61,190$.

DAVID, J. R., ALLEMAND, R., VAN HERREWEGE, J. AND COHET, Y. 1983. Ecophysiology: Abiotic factors. In: Ashburner, M., Carson, H. L. and Thompson, J. N. (eds), The Genetics and Biology of Drosophila, Vol. 3d, Academic Press, London, pp. 103-170.

GEER, B. W., LANGEVIN, M. L. AND MCKECHNIE, S. W. 1985. Dietary ethanol and lipid synthesis in Drosophila melanogaster. Biochem. Genet., 23, 607-622.

GEER, B. W., MCKECHNIE, S. W. AND LANGEVIN, M. L. 1983. Regulation of $s n$-glycerol-3-phosphate dehydrogenase in Drosophila melanogaster larvae by dietary ethanol and sucrose. J. Nutr., 113, 1632-1642.

HARTL, D. L. AND ClarK, A. G. 1989. Principles of population genetics. Sinauer Associates, Inc., Sunderland, Massachusetts.

HEINSTRA, P. W. H., SEYKENS, D., FRERIKSEN, A. AND GEER, B. W. 1990. Metabolic physiology of alcohol degradation and adaptation in Drosophila larvae as studied by means of carbon-13 nuclear magnetic resonance spectroscopy. Insect Biochem., 20, 343-348.

HEINSTRA, P. W. H., THÖRIG, G. E. W., SCHARLOO, W., DRENTH, W. AND NOLTE, R. J. M. 1988. Kinetics and thermodynamics of ethanol oxidation catalyzed by genetic variants of the alcohol dehydrogenase from Drosophila melanogaster and D. simulans. Biochim. biophys. Acta, 967, 224-233.

IZQUIERDO, J. I. AND RUBIO, J. 1989. Allozyme polymorphism at the $\alpha G p d h$ and $A d h$ loci and fitness in Drosophila melanogaster. Heredity, 63, 343-352.

KERVER, J. W. M. AND VAN DELDEN, w. 1985. Development of tolerance to ethanol in relation to the alcohol dehydrogenase locus in Drosophila melanogaster. I. Adult and eggto-adult survival in relation to ADH activity. Heredity, 55, 355-367.

KNIBB, W. R., OAKESHOTT, J. G. AND WILSON, S. R. 1987. Chromosome inversion polymorphisms in Drosophila melanogaster. IV. Inversion and $A d h$ allele frequency changes under selection for different development times. Heredity, 59, 95-104.

KOHANE, M. J. AND PARSONS, P. A. 1986. Environment-dependent fitness differences in Drosophila melanogaster: temperature, domestication and the alcohol dehydrogenase locus. Heredity, 57, 289-304.

LAURIE-AHLBERG, C. C. 1985. Genetic variation affecting the expression of enzyme-coding genes in Drosophila. In: Rattazzi, M. C., Scandalios, J. G. and Whitt, G. S. (eds), Isozymes: Current Topics in Biological and Medical Research, Vol. 12, Alan Liss Inc., New York, pp. 33-88.

MCELFRESH, K. C. AND MCDONALD, J. F. 1986. The effect of temperature on biochemical and molecular properties of Drosophila alchol dehydrogenase. Biochem. Genet., 24, 873-889.

MCKECHNIE, S. W., KOHANE, M. AND PHILIPS, S. C. 1981. A search for interacting polymorphic enzyme loci in Drosophila melanogaster. In: Gibson, J. B. and Oakeshott, J. G. (eds), Genetic Studies of Drosophila Populations, Australian National University Press, Canberra, pp. 121-138. 
MCKECHNIE, S. W. AND GEER, B. w. 1988. The epistasis of $A d h$ and $G p d h$ allozymes and variation in the ethanol tolerance of Drosophila melanogaster larvae. Genet. Res., Camb., 52, 179-184.

MARINKOVIC, D., TUCIC, N., MOYA, A. AND AYALA, F. J. 1987. Genetic diversity and linkage disequilibrium in Drosophila melanogaster with different rates of development. Genetics, 117, 513-520.

MIDDLETON, R. J. AND KACSER, H. 1983. Enzyme variation, metabolic flux and fitness: alcohol dehydrogenase in Drosophila melanogaster. Genetics, 105, 633-650.

MILLER, S., PEARCY, R. W. AND BERGER, E. 1975. Polymorphism at the $\alpha$-glycerophosphate dehydrogenase locus in Drosophila melanogaster. I. Properties of adult allozymes. Biochem. Genet., 13, 175-188.

MITTLER, S. AND BENNETT, J. 1962. A simple food medium that requires no live yeast with the minimum of variables. Dros. Inf. Serv., 36, 131-132.

OAKESHOTT, J. G., GIBSON, J. B., ANDERSON, P. R., KNIBB, W. R., ANDERSON, D. G. AND CHAMBERS, G. K. 1982. Alcohol dehydrogenase and glycerol-3-phosphate dehydrogenase clines in Drosophila melanogaster on different continents. Evolution, 36, 86-96.

OAKESHOTT, J. G., WILSON, S. R. AND PARNELL, P. 1985. Selective effects of temperature on some enzyme polymorphisms in laboratory populations of Drosophila melanogaster. Heredity, 55, 69-82.

O'BRIEN, s. J. AND MACINTYRE, R. J. 1978. Genetics and biochemistry of enzymes and specific proteins of Drosophila. In: Ashburner, M., Carson, H. L. and Thompson, J. N. (eds), The Genetics and Biology of Drosophila, Vol. 2a, Academic Press, London, pp. 396-551.

PALABOST-CHARLES, L. 1980. Maintenance mechanism of polymorphism at the $\alpha-G p d h$ locus in Drosophila melanogaster. Biochem. Genet., 18, 905-913.

PARSONS, P. A. 1983. The Evolutionary Biology of Colonizing Species, Cambridge University Press, New York.

PARTRIDGE, L. 1988. Lifetime reproductive success in Droso- phila. In: Clutton-Brock, T. H. (ed.), Reproductive Success, University of Chicago Press, Chicago, pp. 11-23.

RECHSTEINER, M. C. 1970. Drosophila lactate dehydrogenase and $\alpha$-glycerolphosphate dehydrogenase: distribution and change in activity during development. J. Insect Physiol., 16, 1179-1192.

ROBERTSON, F. W. 1963. The ecological genetics of growth in Drosophila. 6. The genetic correlation between duration of the larval period and body size in relation to larval diet. Genet. Res., Camb., 4, 74-92.

VAN DELDEN, w. 1982. The alcohol dehydrogenase polymorphism in Drosophila melanogaster. Selection at an enzyme locus. Evol. Biol., 15, 187-222.

VAN DELDEN, w. 1984. The alchol dehydrogenase polymorphism in Drosophila melanogaster, facts and problems. In: Wöhrmann, K. and Loeschke, V. (eds), Population Biology and Evolution, Springer-Verlag, Berlin, pp. 127-142.

VAN DELDEN, W. AND KAMPING, A. 1979. The alcohol dehydrogenase polymorphism in populations of Drosophila melanogaster. 3. Differences in developmental times. Genet. Res., Camb., 33, 15-27.

VAN DELDEN, w. AND KAMPING, A. 1989. The association between the polymorphisms at the $A d h$ and $\alpha G p d h$ loci in the $\operatorname{In}(2 L) t$ inversion in Drosophila melanogaster in relation to temperature. Evolution, 43, 775-793.

VIGUE, C. L., WEISGRAM, P. A. AND Rosenthal, E. 1982. Selection at the alcohol dehydrogenase locus of Drosophila melanogaster: effects of ethanol and temperature. Biochem. Genet., 20, 681-688.

ZERA, A. J., KOEHN, R. K. AND HALL, J. G. 1984. Allozymes and biological adaptation. In: Kerkut, G. A. and Gilbert, L. I. (eds), Comprehensive Insect Physiology, Vol. 10, Pergamon Press, New York, pp. 633-674.

ZWAAN, B. J., BIJLSMA, R. AND HOEKSTRA, R. F. 1991. On the developmental theory of ageing. I. Starvation resistance and longevity in Drosophila melanogaster in relation to pre-adult breeding conditions. Heredity, 60, 29-39. 